\title{
Effect of Ellipsoidal Modulus and Internal Pressure on Bearing Capacity of Thrust-Bearing Aft Dome
}

\author{
Wang Peng ${ }^{1}$, Fan Ruixiang ${ }^{2, a}$, Huang Cheng ${ }^{1}$, Yan Dongyang ${ }^{1}$ and Wang Feifan ${ }^{1}$ \\ ${ }^{1}$ Beijing Institute of Astronautical Systems Engineering, Beijing 100076, China \\ ${ }^{2}$ China Academy of Launch Vehicle Technology, Beijing 100076, China
}

\begin{abstract}
In order to analyse the effect of ellipsoidal modulus and internal pressure on bearing capacity of thrust-bearing aft dome, we obtain the stress and strain distribution and bearing capacity of 1.6, 1.4 and 1.0 modulus ellipsoidal aft dome under $0 \mathrm{MPa} \sim 0.98 \mathrm{MPa}$ internal pressure and engine thrust by finite element method. We find as the modulus decreases, the bearing capacity of the ellipsoidal aft dome increases, and as internal pressure decreases, within the engineering range $(0 \sim 0.98 \mathrm{MPa})$, the bearing capacity increases. The conclusion can provide a guidance for the design of thrust-bearing aft dome.
\end{abstract}

\section{Introduction}

At present, the main structural forms of liquid rocket engine thrust transmission are of rods, beam, shell and load-bearing aft dome of tank, etc. [1]. Among them, the form of load-bearing aft dome means engine transmits its thrust directly or by a small frame to the aft dome. This form can obviously reduce the size of frame and even cancel the frame to reduce the mass of the structure, which is of great significance to the lightweight design of the rocket structure.

There are many applications of load-bearing aft dome. For example, Saturn V S-IVB stage transmits thrust to aft dome through a conical shell $[2,3]$, as shown in figure 1 . The Long March 4 third stage transmits the thrust to the aft dome of tank through a cylindrical shell frame called the engine cabin [4-6] , as shown in figure 2. The upper stage Centaur transmits all thrust through a thrust barrel welded to the aft dome [2,7], as shown in figure 3.

There is little literature to discuss the Effect of the parameter designed on bearing capacity of Thrust-Bearing Aft Dome. And the design of Thrust-Bearing Aft Dome lacks guidance. So we use the finite element method to study the Effect of Ellipsoidal Modulus and Internal Pressure on bearing capacity of thrust-bearing aft dome .

\footnotetext{
${ }^{\mathrm{a}}$ Corresponding author : fanruixiang_calt@163.com
} 


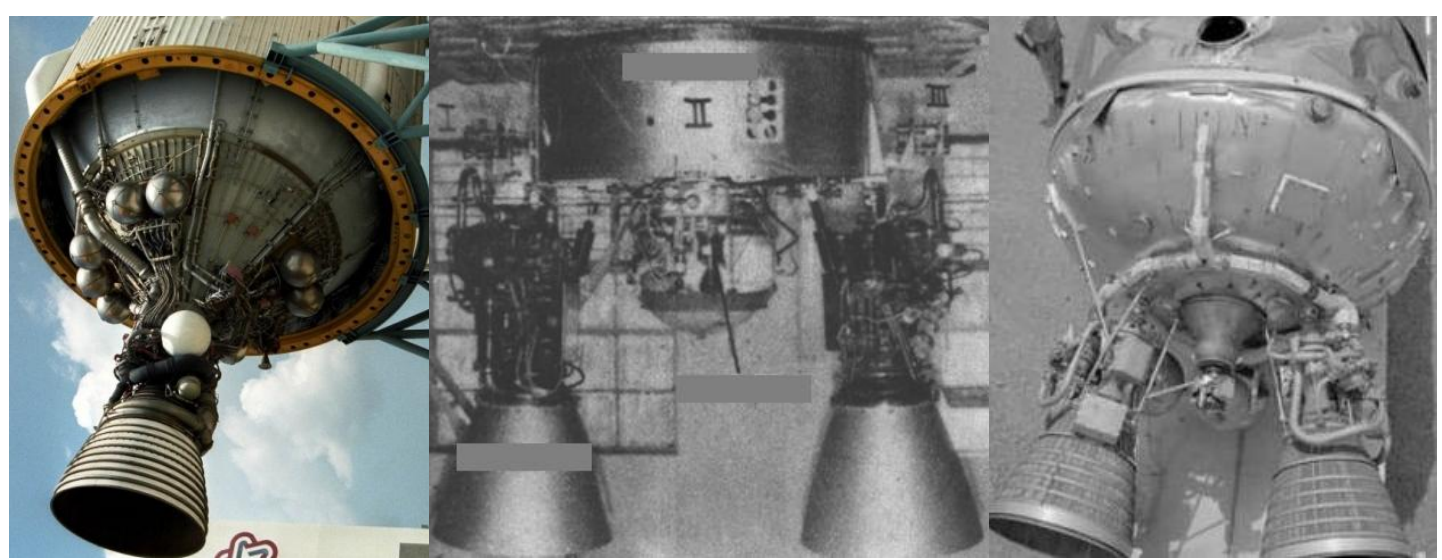

Figure 1. Saturn S-IVB

Figure 2. Third stage of Long March 4

Figure 3. Centaur $\mathrm{C}$ upper stage

\section{FEM MODELS}

The model for analysis consist of aft dome, Y-ring, aft skirt, partial tank barrel and thrust ring (bearing thrust). Figure 4 shows an Ellipsoidal aft dome of 1.6 modulus. The specific dimensions are as follows: tank outer diameter: $3350 \mathrm{~mm}$, Ellipsoidal Modulus of aft dome: 1.6, 1.4 and 1.0(spherical aft dome), aft dome thickness: $5 \mathrm{~mm}$; tank barrel thickness: $8 \mathrm{~mm}$, height: $300 \mathrm{~mm}$; aft skirt thickness: $8 \mathrm{~mm}$, aft skirt and Y-ring total height: $300 \mathrm{~mm}$, Concave vertices of Y-ring away from the bottom of aft skirt: $185 \mathrm{~mm}$,as shown in figure 5; thrust ring Inner diameter: $1380 \mathrm{~mm}$, Outer diameter: $1430 \mathrm{~mm}$, the thrust ring outer height: $37 \mathrm{~mm}$, as shown in figure 6 . Corner radius is $2 \mathrm{~mm}$ in the model.

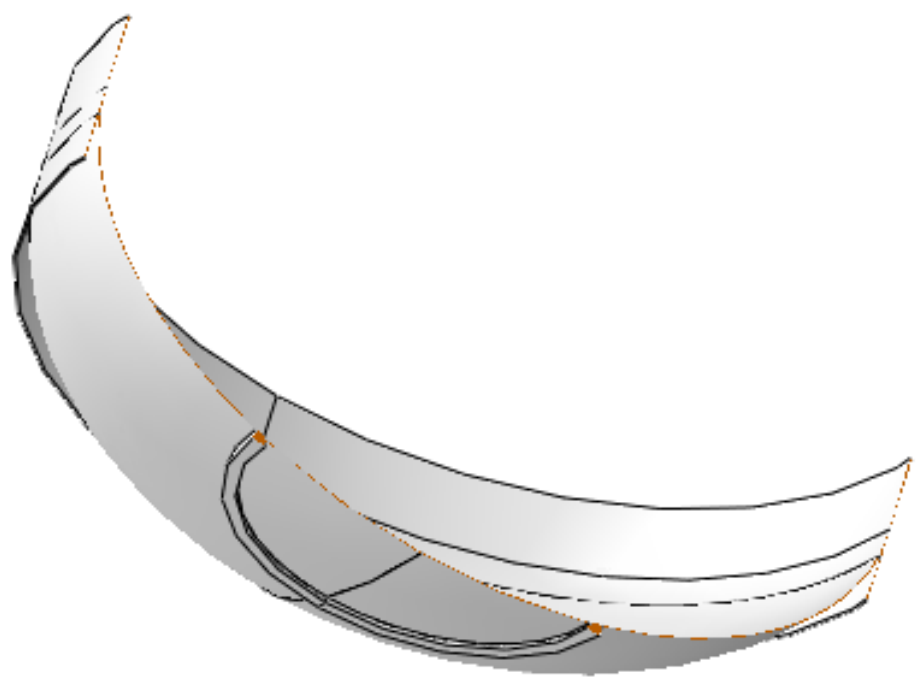

Figure 4. Symmetry plane section of 1.6 modulus aft dome 


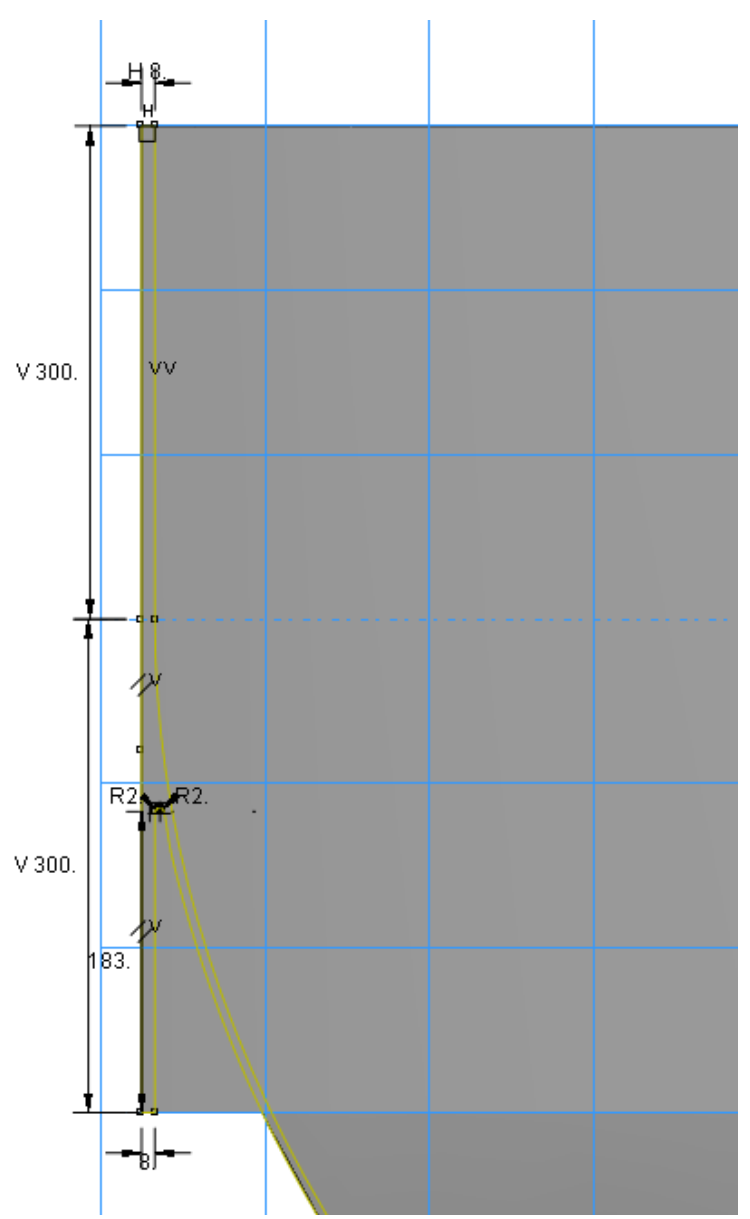

Figure 5. Dimension of Y-ring

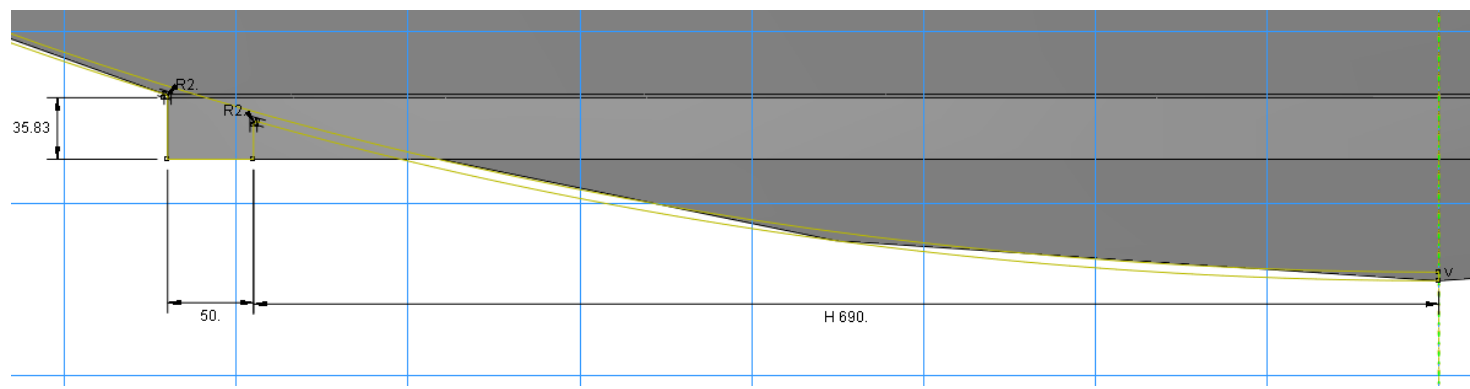

Figure 6. Position and dimension of thrust ring

Material parameters:

elastic modulus: 69000MPa, Poisson's ratio: 0.32 , Density: $2.7 \mathrm{e} 3 \mathrm{~kg} / \mathrm{m}^{3}$. Set nlgeom on in analysis step; the top of the barrel is fixed in the constraint. The grid uses C3D8I type.The internal pressure setting is shown in table 1 . Thrust load is set to $2000 \mathrm{kN}$.

Table 1. Internal pressure setting

\begin{tabular}{|l|l|l|l|l|l|l|l|l|l|l|l|}
\hline Internal pressure $(\mathrm{MPa})$ & 0 & 0.08 & 0.18 & 0.28 & 0.38 & 0.48 & 0.58 & 0.68 & 0.78 & 0.88 & 0.98 \\
\hline
\end{tabular}




\section{RESULT}

\section{1 stress distribution}

Within the range of load-bearing capacity, the stress distribution of the three moduli $(1.6,1.4,1.0)$ aft dome under thrust and different internal pressure $(0 \sim 0.98 \mathrm{MPa})$ is the same. The overall trend of the stress is that the stress gradually increases from the centre of aft dome outward along the radial direction. A ring area with a relatively high stress appears at a radial distance of about $120 \mathrm{~mm}$ outside the thrust ring. When the load limit is reached, the maximum stress appears here. Figure 7 shows the Von Mises stress contour of 1.6 modulus aft dome under $1000 \mathrm{kN}$ thrust and $0.38 \mathrm{MPa}$ internal pressure, and Von Mises stress reaches $216.4 \mathrm{MPa}$ in the high stress area. The stress at the centre of aft dome is $104.9 \mathrm{MPa}$.
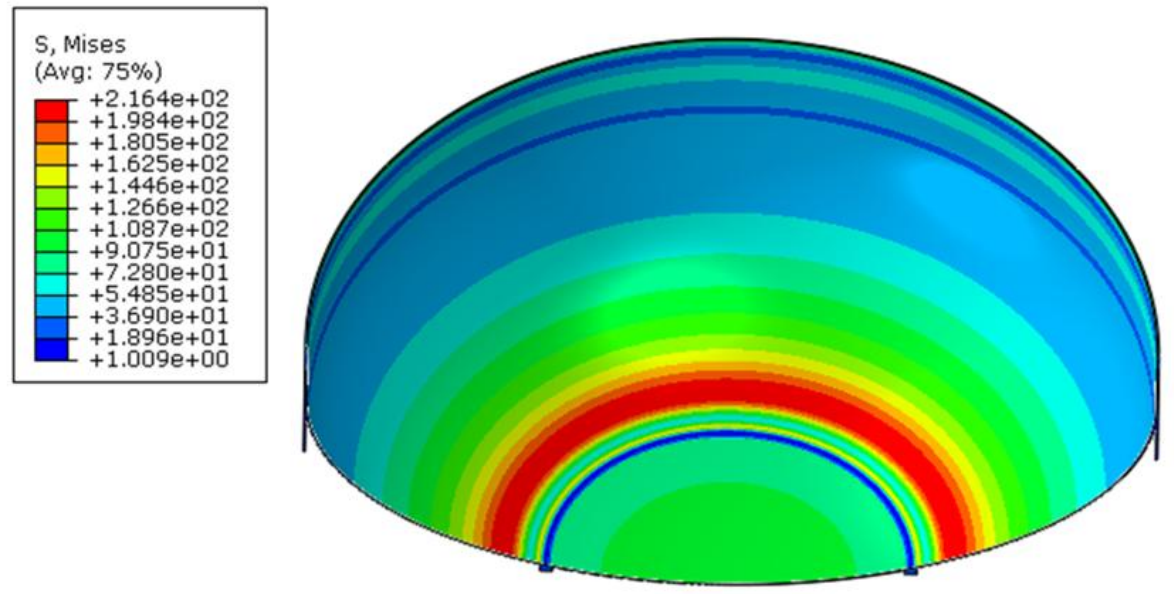

Figure 7. Von Mises stress contour of 1.6 modulus aft dome under $0.38 \mathrm{MPa}$ internal pressure and $1000 \mathrm{kN}$ thrust

At the same time, we obtain the stress distribution of aft dome when there is only internal pressure load. Figure 8 shows the Von Mises stress contour of 1.6 modulus aft dome under $0.38 \mathrm{MPa}$ pressure. The maximum stress appears in the centre of the aft dome. And the stress reaches 104.9 MPa, which is the same in Figure 7. This shows that the stress at the centre of the aft dome is independent of the thrust and is only related to the internal Pressure.

Comparing the maximum stress area in Figure 7, the stress at the same area in fig 3-2 is $80 \mathrm{MPa}$ when there is only internal pressure. It can be seen that the increase in thrust causes a significant increase in the stress in the area. 


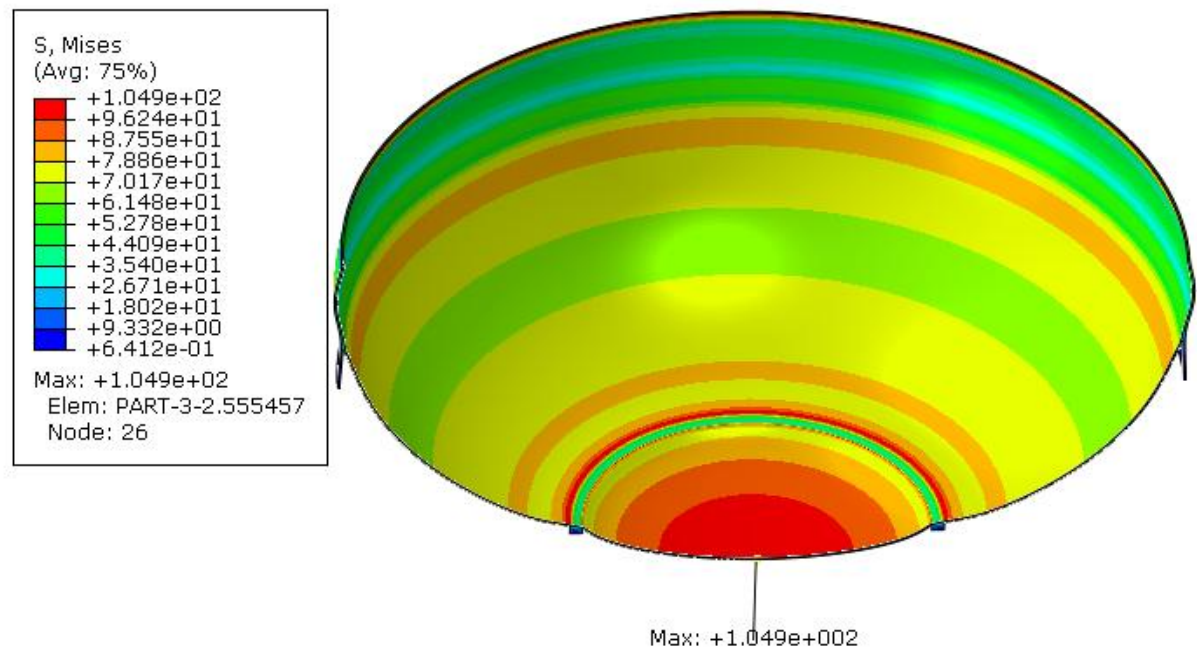

Figure 8. Von Mises stress contour of 1.6 modulus aft dome under 0.38MPa internal pressure

\subsection{Deformation distribution}

The Deformation distribution of the three moduli $(1.6,1.4,1.0)$ aft dome under thrust and different internal pressure $(0 \sim 0.98 \mathrm{MPa})$ is the same. The aft dome deforms outward under the internal pressure, as shown in figure 9. It can be seen that the thrust ring has certain restraining effect on the expansion deformation of the aft dome. In the next step, the thrust load is applied and the thrust ring area deforms in the opposite direction against the internal pressure, forming the deformation in figure 10. Figure 10 is the displacement contour (U2-along rotary axis, 20x magnification) of 1.6 modulus aft dome under $0.38 \mathrm{MPa}$ internal pressure and $1000 \mathrm{kN}$ thrust.

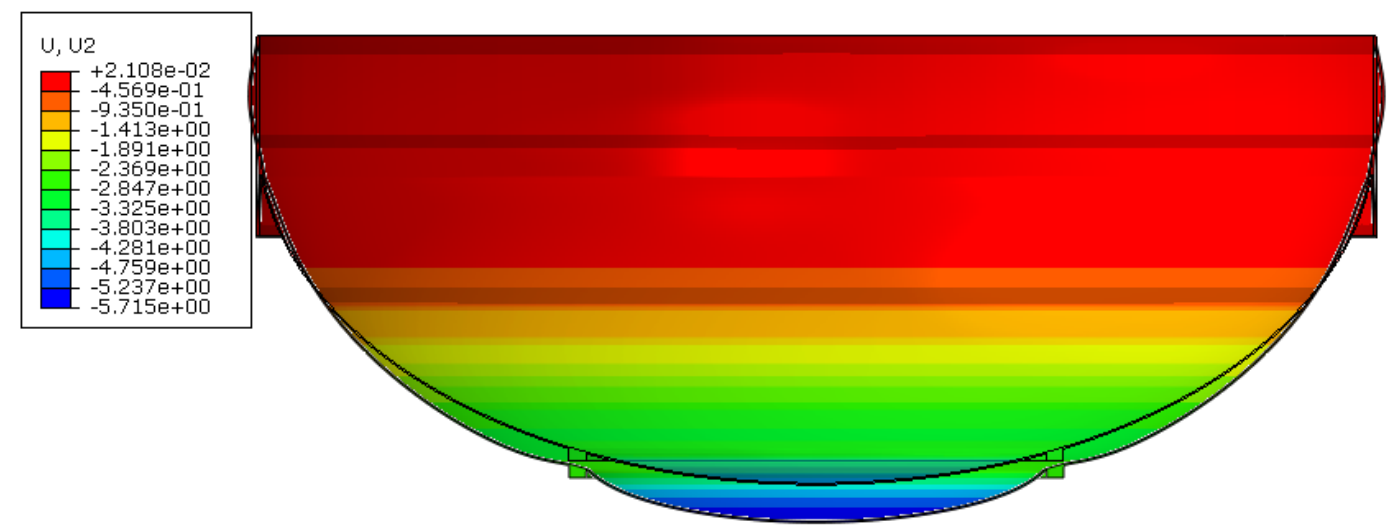

Figure 9. U2 displacement contour of 1.6 modulus aft dome under $0.38 \mathrm{MPa}$ internal pressure (20 times magnification) 


\section{$2 M A E 2018$}

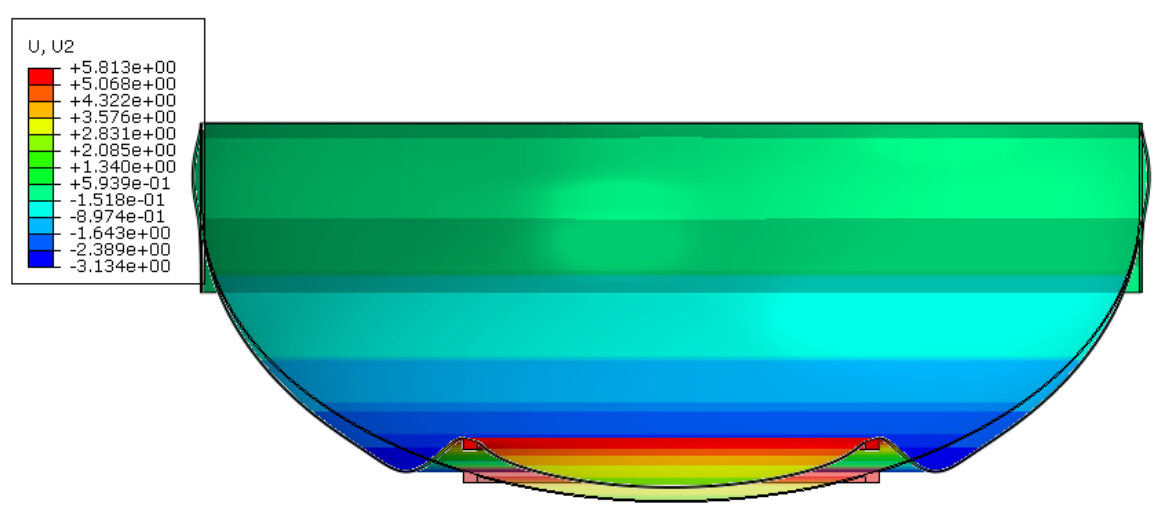

Figure 10. U2 displacement contour of 1.6 modulus aft dome under $0.38 \mathrm{MPa}$ internal pressure and $1000 \mathrm{kN}$ thrust (20 times magnification)

\subsection{Structural failure mode analysis}

Structural failure mode I: The aft dome is buckling due to thrust, resulting in stress in high stress area in Figure 3.7 to yield limit; In failure mode II, the stress in the central area of aft dome reaches the yield limit. In these analyses only does the failure mode I occurred when using the material properties of Aluminum alloy (yield limit $280 \mathrm{MPa}$ ). The occurrence of failure mode II is related to the internal pressure, but not to the thrust. It occurs only when the internal pressure is large, and does not occur in these analyses (the internal pressure is no larger than $0.98 \mathrm{MPa}$ ).

The failure mode I can be observed through the load-displacement curve at the thrust position, as shown in figure 11 . When the thrust gradually increases to $1300 \mathrm{kN}$, the axial displacement (U2) at the thrust area suddenly increases sharply, indicating that buckling occurs here and the bearing capacity Rapidly reduces .During the buckling, In figure 12, the high stress area is severely deformed, resulting in sharply increasing stress.

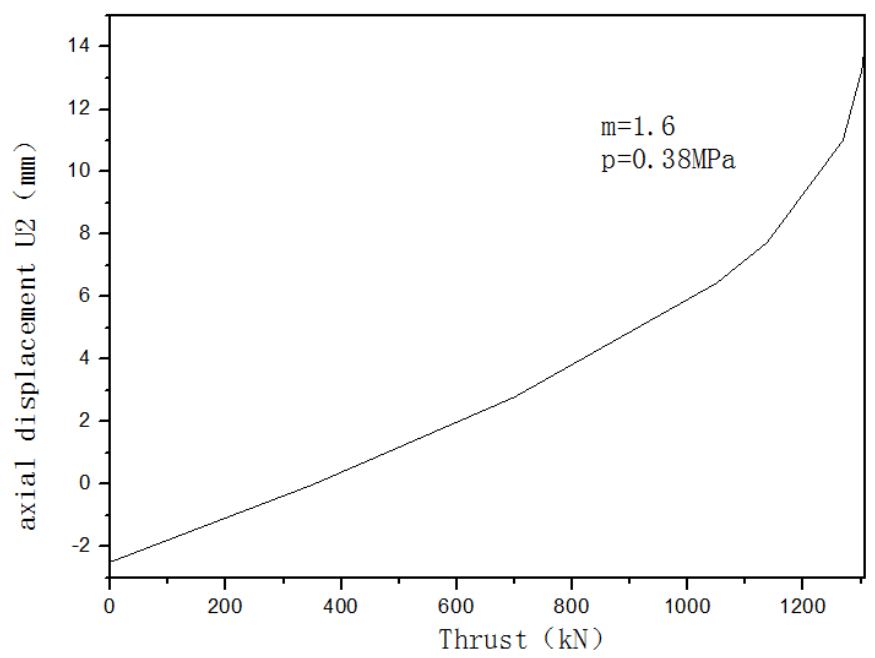

Figure 11. Load-displacement curve at the thrust position of 1.6 modulus aft dome under $0.38 \mathrm{MPa}$ internal pressure and thrust 


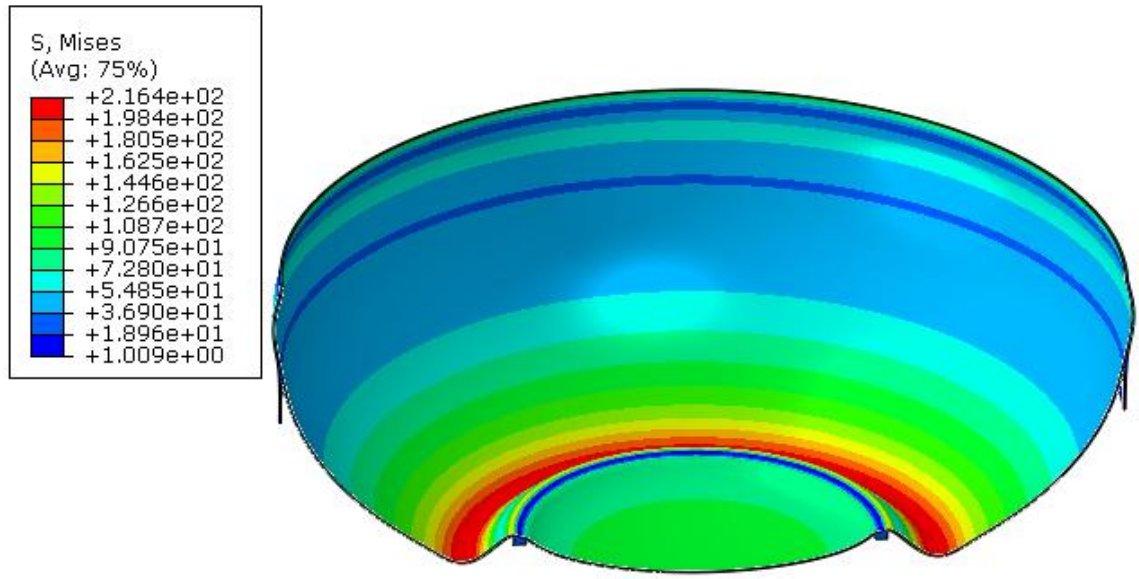

Figure 12. Von Mises stress contour of 1.6 modulus aft dome under $0.38 \mathrm{MPa}$ internal pressure and $1000 \mathrm{kN}$ thrust (20 times magnification deformation)

\subsection{Effect of Ellipsoidal Modulus and Internal Pressure on bearing capacity}

We define bearing capacity as the maximum thrust, under which maximum stress in aft dome reaches $280 \mathrm{MPa}$. In all analysis groups, the deformation of aft dome was within the allowable range when the yield limit was reached, and the maximum deformation was not more than $10 \mathrm{~mm}$.

The results are shown in figure 13.

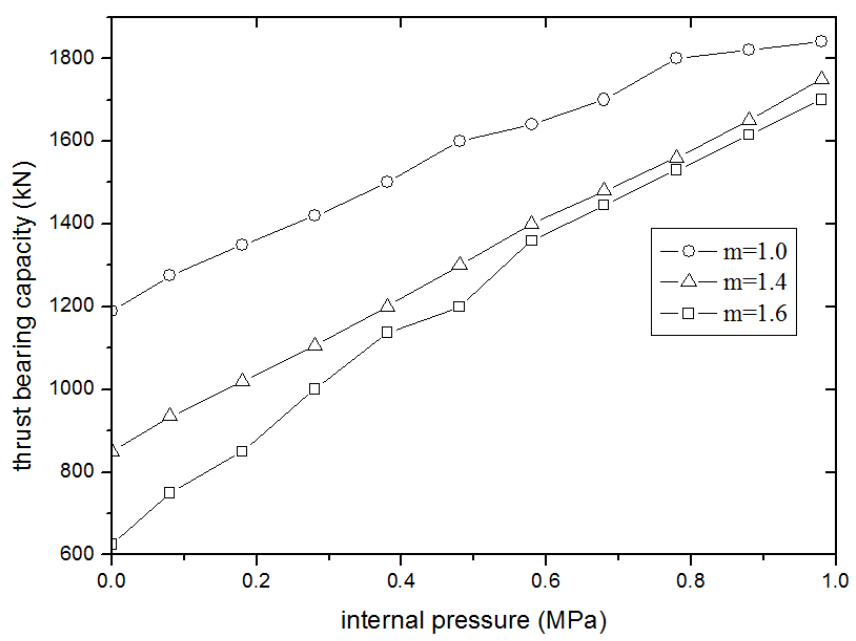

Figure 13. Thrust-bearing capacity of 1.6, 1.4 and 1.0 modulus aft dome under $0 \sim 0.98 \mathrm{MPa}$ internal pressure

we can see that for the material properties set in this analysis (elasticity modulus $69 \mathrm{GPa}$, Poisson's ratio 0.32 , yield strength $280 \mathrm{MPa}$ ), reducing the ellipsoid modulus can improve the bearing capacity under different internal pressures, but At the same time reducing the modulus will increase the mass and the height of the aft dome, as shown in table 2; within the actual engineering pressure range $(0 \sim 0.98 \mathrm{MPa})$, increasing the internal pressure of the tank can significantly increase the bearing capacity of the aft dome

Table 2. Mass and height of 1.6, 1.4 and 1.0 modulus aft dome 


\begin{tabular}{lll}
\hline modulus & mass & Height of model \\
\hline 1.6 & $330 \mathrm{~kg}$ & $1047 \mathrm{~mm}$ \\
1.4 & $344 \mathrm{~kg}$ & $1196 \mathrm{~mm}$ \\
1.0 & $381 \mathrm{~kg}$ & $1675 \mathrm{~mm}$ \\
\hline
\end{tabular}

\section{4 conclusion}

For the material properties (elasticity modulus 69GPa, Poisson's ratio 0.32 , yield strength $280 \mathrm{MPa}$ )

1.Reducing the ellipsoid modulus can improve the bearing capacity under different internal pressures, but at the same time it will increase the mass and height of the aft dome. So In the design, comprehensive consideration should be given to selecting an appropriate modulus.

2. Within the engineering pressure range $(0 \sim 0.98 \mathrm{MPa})$, increasing the internal pressure of the tank can significantly increase the bearing capacity of the aft dome.

\section{References}

1. Zhu Ningchang, Liu guoqiu. Design of Liquid Propellant Rocket Engine, China Astronautic Publishing House, 3(2005)

2. Saturn V. Flight Manual[R]. MSFC-MAN-503, 1 November, (1968)

3. S-4B stage thrust structure influence coefficient.(1970)

4. Xu Xin-hua. Long March launch vehicle[J].Missiles and Spacecraft, 1(1991)

5. Zang Jia-liang. The surface tension tank design selected for the third stage's attitude control engine of Long March launch vehicle[J]. Aerospace China,8(1992)

6. Wu Rui-hua, Gu Song-an. Long March series launch vehicle introduction: Long March 4 series (3) [J]. Aerospace China, 2(1999)

7. San Diego, Titan 3E Centaur D-1T Systems Summary 